\title{
XXX. On an unnoticed danger in certain apparatus for distribution of electricity
}

\section{J. Hopkinson F.R.S.}

To cite this article: J. Hopkinson F.R.S. (1885) XXX. On an unnoticed danger in certain apparatus for distribution of electricity , Philosophical Magazine Series 5, 20:124, 292-295, DOI: $10.1080 / 14786448508627755$

To link to this article: http://dx.doi.org/10.1080/14786448508627755

曲 Published online: 29 Apr 2009.

Submit your article to this journal

Џll Article views: 2

Q View related articles $\square$ 
made to see a system of arrangement in the Pacific islands, instead of a "labyrinth ;" to appreciate the vast length of the island-chains in the great ocean with their many parallelisms, and the accordant relations subsisting between them and long lines of atolls. I was thence led to observe the corresponding system in the features of the continental lands, and the more fully so when afterwards it was proved that Geology was not in America merely the study of strata and fossils, but of the successive stages in a growing continent. Thus a conception of the earth as a unit became early implanted, and the idea also of its development as a unit under movements as comprehensive as the system in its feature-lines. My faith in any mountain-making theory hitherto proposed is weak. But that idea of system in structure and progress stands, and, however much ignored by students of the earth's stratigraphy, it must have its explanation in a true theory of the earth's dynamies.

XXX. On an unnoticed Danger in certain Apparatus for Distribution of Electricity. By J. HopKInson, F.R.S.*

WANY plans have been proposed, and several have been I to a greater or less extent practically used, for combining the advantage of economy arising from a high potential in the conductors which convey the electric current from the place where it is generated with the advantages of a low potential at the various points where the electricity is used. A low potential is necessary where the electricity is used; partly because the lamps, whether arc or incandescent, each require a low potential, and partly because a high potential may easily become dangerous to life. Amongst the plans which have been tried for locally transforming a supply of high potential to a lower and safer, the most promising is by the us $\theta$ of secondary generators or induction-coils. It has been proved that this method can be used with great economy of electric power and with convenience; under proper construction of the induction-coils it may also be perfectly safe. It is, however, easy and very natural so to construct them that they shall be good in all other respects but that of safety to life-that they shall introduce an unexpected risk to those using the supply.

In a distribution of electricity by secondary generators, an alternating current is led in succession through the primary coils of a series of induction-coils, one for each group or system of lamps. The lamps connect the two terminals of the

* Communicated by the Author. 
secondary coil of the induction-coils. It is easy to so construct the induction-coils that the difference of potential between the terminals of the secondary coils may be any suitable number of volts, such as 50 or 100 ; whilst the potential of the primary circuit, as measured between the terminals of the dynamo machine, may be very great, e. $g$. 2000 or 3000 volts. If the electromagnetic action between the primary and secondary coils, on which the useful effect of the arrangement depends, were the only action, the supply would be perfectly safe to the user so long as apparatus with which he could not interfere was in proper order. But the electromagnetic action is not the only one. Theoretically speaking, every induction-coil is also a condenser, and the primary coil acts electrostatically as well as electromagnetically upon the secondary coil. This electrostatic action may easily become dangerous if the secondary generator is so constructed that its electrostatic capacity, regarded as a condenser, is other than a very small quantity.

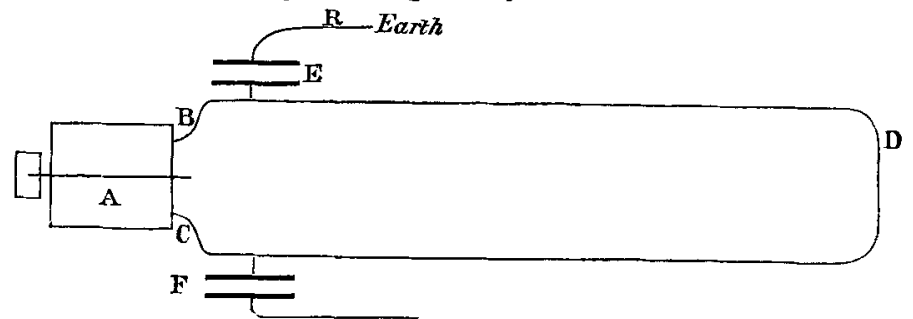

Imagine an alternate-current dynamo machine, $\mathrm{A}$, its terminals, B, C, connected by a continuous conductor, B D C, on which may be resistances, self-induction-coils, secondary generators, or any other appliances; at any point is a condenser, E, one coating of which is connected to the conductor, or may indeed be part of it, the other is connected to earth through a resistance, $R$. Let $K$ be the capacity of the condenser, $V$ the potential at time $t$ of the earth-coating of the condenser, $U$ the potential of the other coating, $x$ the current in resistance $\mathrm{R}$ to the condenser from the earth, being taken as positive, and the earth-potential as zero. We have

whence, since

$$
x=\frac{\mathrm{V}}{\mathrm{R}}, \mathrm{K}\left(\mathrm{U}^{*}-\mathrm{V}^{*}\right)=x ;
$$

$$
\mathrm{U}=\mathrm{A} \sin 2 \pi n t
$$

where $A$ is a constant depending on the circumstances of the dynamo circuit as well as the electromotive force of the machine, and $n$ is the reciprocal of the periodic time of the 
machine, we have

$$
\begin{gathered}
\mathrm{KR} \dot{x}+x=2 \pi n \mathrm{KA} \cos 2 \pi n t, \\
x=\frac{2 \pi n \mathrm{KA}}{(\mathrm{KR} 2 \pi n)^{2}+1}\{-2 \pi n \mathrm{KR} \sin 2 \pi n t+\cos 2 \pi n t\}, \\
\text { mean square of } x=\frac{2 \pi n \mathrm{~K}}{\sqrt{(\overline{\mathrm{KR}} 2 \pi n)^{2}+1}} \text {. mean square of A. }
\end{gathered}
$$

Let us now consider the actual values likely to occur in practice. Let the condenser $\mathrm{E}$ be a secondary generator; let the resistance $R$ be that of some person touching some part of the secondary circuit, and also making contact to earth with some other part of the body ; $n$ may be anything from 100 to 250 , say $150 ; \mathrm{K}$ will depend on the construction of the secondary generator -it may be as high as 0.3 microfarad or even more, but there would be no difficulty even in large instruments in keeping it down to one hundredth of this or less. The mean square of $A$ will depend on the circumstances of other parts of the circuit; it might very easily be as great, or very nearly as great, as the mean difference of potential between the terminals of the machine if the primary circuit were to earth at C. Suppose, however, that the circuit B D C is symmetrical, that $E$ is at one end, and that another person of the same resistance as the person at $\mathrm{E}$ is touching the secondary circuit of the secondary generator $F$ at the other end of the circuit. In that case, if 2400 be difference of potential of the machine, mean square of $\mathrm{A}$ will be 1200 ; in which case we have, taking $R$ as 2000 ohms,

$$
\text { mean square of } \begin{aligned}
x & =\frac{2 \pi \times 150 \times 0.3 \times 10^{-6}}{\sqrt{\left(2 \pi \times 150 \times 0.3 \times 10^{-6} \times 2000\right)^{2}+1}} \times 1200 \\
& =\text { about } 0.3 \text { ampere. }
\end{aligned}
$$

Experiments are still wanting to show what current may be considered as certain to kill a man, but it is very doubtful whether any man could stand 0.3 ampere for a sensible length of time. It is probable that if the two persons both took firm hold of the secondary conductors of $\mathrm{E}$ and $\mathrm{F}$, both wonld be killed. If the person at $\mathrm{F}$ be replaced by an accidental dead earth on the secondary circuit of $F$, the person at $E$ would experience a greater current than 0.3 ampere.

It follows from the preceding consideration that secondary generators of large electrostatic capacity are essentially dangerous, even though the insulation of the primary circuit and of the primary coils from the secondary coils is perfect. The moral is-for the constructor, Take care that the secondary generators have not a large electrostatic capacity, say not 
more than 0.03 microfarad, better less than ${ }_{10}^{1} \overline{0}$ microfarad; for the inspector, Test the system for safety. The test is very easy. Place a secondary generator of greatest capacity at one end of the line and connect its secondary circuit to earth through any instrument suitable for measuring alternate currents under one ampere ; put the other end of the primary to earth; the reading of the current-measuring instrument should not exceed such a current as it may be demonstrated a man can endure with safety.

XXXI. On Supersaturation of Salt-Solutions. By W. W. J. Nicol, M.A., D.Sc., F.R.S., Lecturer on Chemistry, Mason College, Birmingham*.

TN my previous paper $\dagger$ on this subject I described experi1 ments which proved that a so-called supersaturated solution was able to dissolve more of the salt it already contained, provided only that the salt was added in the dehydrated state, and under conditions which precluded the possibility of access of crystals of the hydrater salt. I also expressed the opinion that a supersaturated solution is merely a solution of the anhydrous salt which may, or may not, be saturated; and that it differs in no way from an ordinary solution so long as no disturbing cause operates to bring about the formation of a hydrate which exists only in the solid state.

Until I made the experiments described in the following paper, I was of the opinion that although a bydrated salt existed in solution in what may be termed an anhydrous state, still, when a dehydrated salt is dissolved in pure water, solution always took place in two stages-the first consisting of the hydration of the salt to form the solid hydrate, and that this was followed by solution accompanied by the decomposition of the hydrate thus formed; but the experiments I am about to describe are, I think, conclusive, and show clearly that solution of the dehydrated salt in pure water is unattended by the formation of any hydrate, solid or liquid.

Two similar wide-mouthed bottles, capable of holding some 60 cubic centim. of water, were taken; in each were placed 25 eubic centim. of the same sample of distilled water, and in each a glass bulb containing 5 grms. of dehydrated $\mathrm{Na}_{2} \mathrm{SO}_{4}$. One of the bottles (No.1) was placed at once in the constanttemperature bath at $20^{\circ} \mathrm{C}$.; the other (No. 2) was placed in a water-bath which was raised to the boiling-point; it was then, after cooling, placed alongside the first bottle. After

* Communicated by the Author.

+ Phil. Mag. June 1885. 